\title{
Nuevos Senderos de la Agroindustria de la Papa
}

\author{
Gregory Scott, ${ }^{1}$ Luís Maldonado ${ }^{2}$ y Víctor Suárez'
}

\begin{abstract}
Resumen
A pesar de su relevancia actual entre los diez cultivos alimenticios más importantes en los países en desarrollo, la papa rara vez es citada por su potencial agroindustrial o como un bien transable. El presente trabajo analiza las tendencias recientes de la agroindustria y comercio de la papa en América Latina. Por medio de una tipología de países se intenta aclarar la situación actual y opciones relevantes para el futuro de cada tipo de país. Así, se nota que en la mayoría de los casos, para realzar el potencial de la papa no solamente se requiere nuevas variedades aptas para el procesamiento, sino también actividades e iniciativas que mejoren a la vez varios aspectos de la producción, comercialización y transformación del cultivo, como ya lo apreciamos en algunos países de

la región.
\end{abstract}

\section{Introducción}

Las implicancias para la política agraria sobre el incremento de la liberalización y globalización del comercio para los países en desarrollo han merecido un reciente debate. En su mayor parte, éste se ha centrado en los cereales, ganadería, productos lácteos, frutas, y vegetales frescos. No obstante, hoy en día hay mucho más interés en América Latina por las tendencias y potencial de productos secundarios como posibles ejes de desarrollo económico local y fuentes de divisas no-tradicionales; y ello se debe precisamente a que el comportamiento de dichos productos en la economía regional no ha sido objeto de investigaciones detalladas, tampoco han sido objeto de una serie de políticas destinadas a explotar su potencial. La papa es justamente uno de esos productos. A pesar del actual puesto en relación a los diez cultivos alimenticios más importantes en los países en desarrollo, la papa rara vez es citada por su potencial agroindustrial; mucho menos como producto para exportación. De hecho, la actual industrialización de papa es, en muchos casos, más importante de lo que era hace unos años (Scott, Basay y Maldonado 1997). Además, por lo general los estudios de

${ }^{1}$ Economista, Centro Internacional de la Papa. Apartado Postal 1558, Lima, Perú.

2 Asistentes de investigación. Centro Internacional de la Papa, Apartado Postal 1558, Lima 12, Perú.

Correo electrónico: I.maldonado@cgiar.org y/o v.suarez@CQiar.orq' 
caso publicados sobre el comercio de la papa sólo informan sobre el comercio interno y en forma fresca, dejando de lado los datos sobre el comercio exterior de productos procesados tales como papas fritas congeladas y hojuelas de papas.

Después de una breve revisión de las tendencias globales en la producción y el comercio, este trabajo analiza las tendencias recientes de la agroindustria y el comercio de la papa y sus productos derivados en América Latina. Nuestro principal interés es demostrar que: (1) por varias razones la agroindustria y el comercio exterior ya tienen una creciente influencia sobre la evolución de la producción de la papa en la región, pero dicho comportamiento y su Impacto sobre el subsector han sido muy desiguales; (2) los funcionarios públicos, empresarios, agricultores y los investigadores de la papa en estos países deberían tomar las acciones apropiadas para mantenerse competitivos en los siguientes años, pero dichas acciones tendrían más probabilidad de éxito si corresponden a la situación en que se encuentra el subsector; y (3) en muchos casos las medidas requeridas para mejorar la competitividad involucrarán, necesariamente, la búsqueda de nuevos participantes -más allá de aquellos tradicionalmente comprometidos en actividades relacionadas con el mejoramiento de la producción de papa para su venta doméstica y su uso en forma fresca.

Los resultados presentados en este trabajo sintetizan la información recolectada de una amplia variedad de fuentes. Esto incluye los datos publicados y los no publicados de la FAO sobre comercio; las estadísticas de comercio del USDA; entrevistas informales con los industriales y los institutos nacionales de investigación agraria en varios de los países latinoamericanos; y figuras y análisis recogidos de la "literatura gris". Esta comprende, por ejemplo, artículos en periódicos, informes no publicados, aquella información recolectada durante las visitas realizadas a los países latinoamericanos en años anteriores, e información perteneciente a Informes desarrollados por el sector privado.

El método combina un análisis histórico de series de tiempo de los datos de importaciones y exportaciones con una tipología de países. De este modo esperamos proveer una idea más clara de las considerables diferencias que existen -por el tiempo y la ubicación, así como por la naturaleza y la trayectoria en relación a la agroindustria y comercie- en los distintos países de América Latina.

\section{Cambios globales y regionales en la oferta de papa}

En los últimos tres decenios, los cambios en la oferta de papa han transformado el sector. A nivel mundial, estos cambios son fundamentalmente tres.

Primero. En la década de los noventa, la producción de papa en los países en desarrollo entró en una nueva fase de rápida expansión. A principios de la década, la producción superó los 100 millones de 
toneladas, en comparación con menos de 30 millones de toneladas producidas a principios de los sesenta. Durante los diez últimos años, la producción de papa ha aumentado en un promedio anual de $4.8 \%$, con un aumento en el área sembrada de $2.2 \%$. Entonces, mientras la producción de papa sigue en aumento, el promedio de crecimiento para el área sembrada y producción continúa acelerándose (Figura 1).

Segundo. En años recientes la tasa de crecimiento en la producción para el maíz, trigo y arroz ha disminuido, mientras que la tasa de crecimiento de producción de papa se ha acelerado, aumentando así su importancia relativa frente a otros alimentos, especialmente en Asia (Figura 2).

Tercero. Según la última información de la $\mathrm{FAO}$, la producción de papa a nivel mundial se mantiene en alrededor de 296 millones de toneladas y cubre más de 18 millones de hectáreas. Con la desintegración de la ex Unión Soviética, actualmente China es el mayor productor de papa a nivel mundial. La India ocupa el cuarto lugar. A pesar de que la producción de papa en Europa ha disminuido desde principios de los sesenta, esta disminución ha sido más que compensada con el crecimiento en Asia, África y América Latina, lo cual explica el aumento global en la producción de toneladas de papa. Estas prolongadas y cada vez más divergentes tendencias de producción en Europa con relación a los países en desarrollo reflejan los actuales cambios fundamentales en la economía global de la papa. En los últimos cuatro años, el porcentaje de producción de papa a nivel mundial en los países en desarrollo aumentó de $31 \%$ a $41 \%$ (Figura 3). Así, este progreso reafirma la creciente importancia de la papa como fuente de alimento, trabajo e ingresos para el Asia, África y América Latina.

En América Latina, los cambios en la oferta de papa refiere a cuatro tendencias. La primera es la tasa de crecimiento de la producción de papa: $2.4 \%$ en promedio en América Latina, en los últimos 40 años (véase Cuadro 1). Sobre esa tendencia, tres observaciones son claves. A pesar de ser una tasa relativamente alta, es notablemente inferior a las de Asia y África por el mismo periodo (Cuadro 2). Es notable también que dicho incremento se debe exclusivamente al aumento de la productividad; entre 1961-63 y 1997-99 los rendimientos promedio por hectárea pasaron de 7 a $14 \mathrm{t} / \mathrm{ha}$, superiores a los de regiones como Asia y África e incluso a los rendimientos mundiales y de muchos países en desarrollo (Scott y Maldonado, 1998). Las diferencias en el ritmo de crecimiento de los rendimientos al interior de América Latina revelan el enorme potencial para acrecentar la productividad del productor de papa en la región (Cuadro 1). 
Figura 1. Promedio del crecimiento anual de la papa en países en desarrollo a intervalos de 10 años desde 1961-99

Tasa de crecimiento (\%)

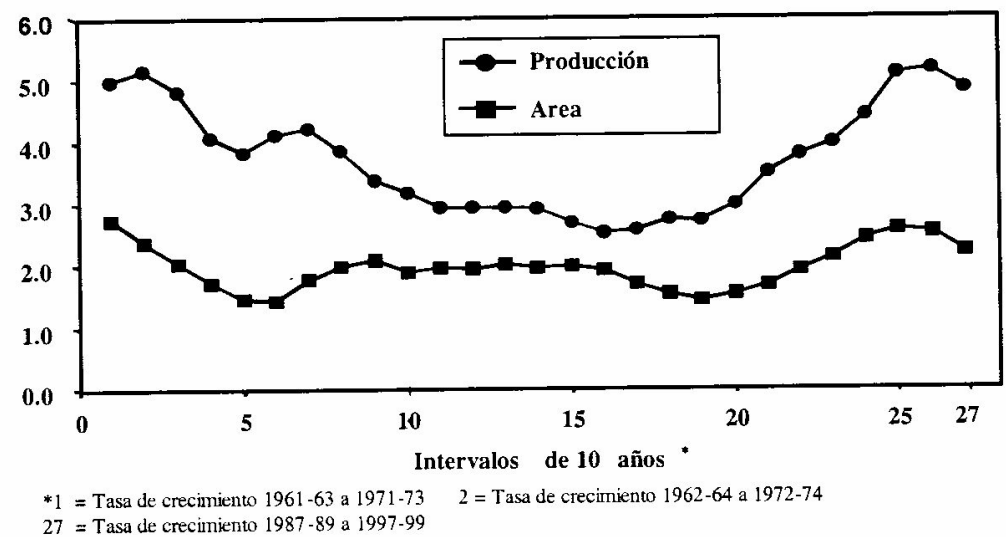

Fuente: FAOSTAT, 5 abril 2000.

Figura 2. Promedio del crecimiento anual de la producción de ciertos cultivos en países en desarrollo: 1987-89 a 1997-99 y 1961-63 a 1997-99

Tasa de crecimiento \%

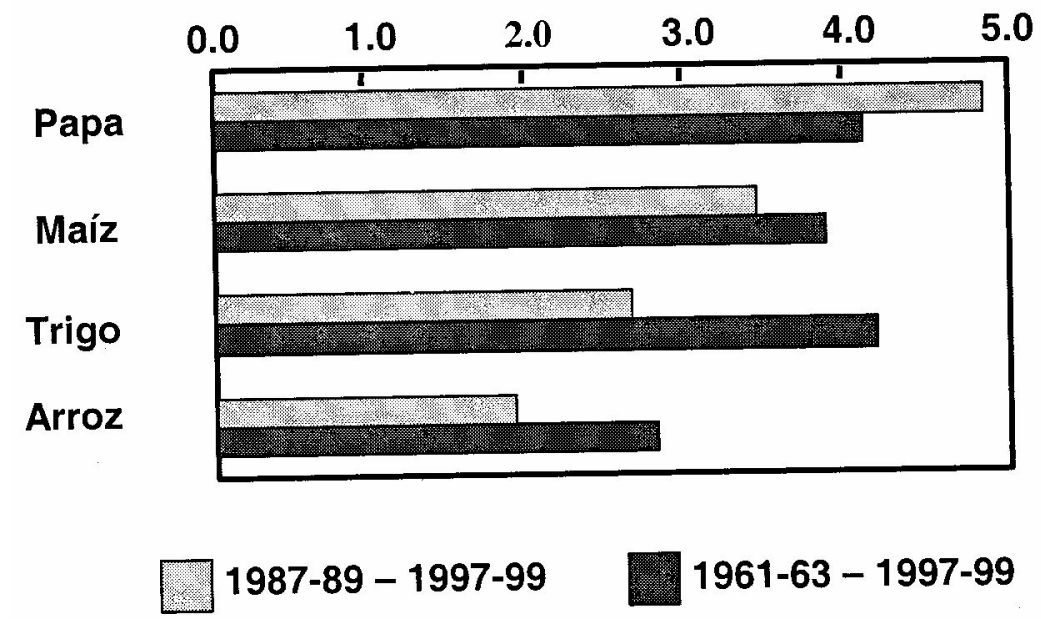

Fuente: FAOSTAT, 5 abril 2000 
Figura 3. Producción glñobalde papa (000 t), 1961-99

$1961-63=264,504$

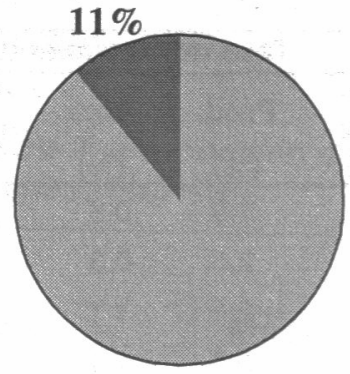

$1991-93=277,722$

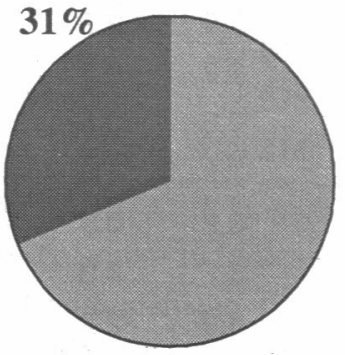

Paises en desarrollo
$1975-77=274,273$

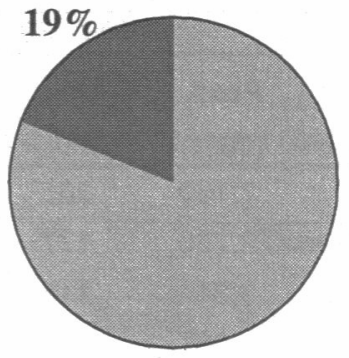

$1997-99=296,422$

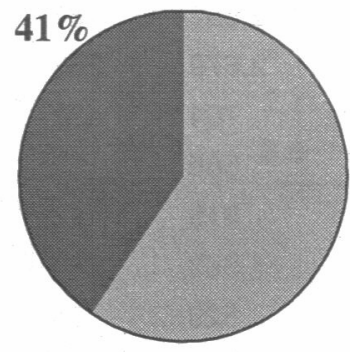

Paises industrializados

Fuente: FAOSTAT, 5 abril 2000.

Fuente: FAOSTAT, 5 abril 2000.

La segunda tendencia sobre el aspecto de la oferta en América Latina se refiere a los cambios dentro del sector, es decir, una mayor orientación comercial de la producción en general y una menor para la autosubsistencia en papa. La tendencia a reducir el área sembrada en muchos países en América Latina ha llevado a que la producción se concentre en las áreas de mayor productividad que, por tanto, disponen de mayores excedentes comercializables. Esto se ha debido a la libre competencia -en la medida en que se produce para la venta y no para el consumo propio-, en la que sobreviven sólo los productores más eficientes. Así, por ejemplo, en Brasil la producción de papa se ha concentrando en el centro y sudeste del país, en provincias donde es mayoritariamente comercial y los insumos se utilizan de modo más eficiente. También en los países andinos como Perú y Bolivia, tradicionalmente productores 
para el autoconsumo, la agricultura papera está cada vez más vinculada al mercado (Mayer et al. 1992; Thiele et al. 1998; Zevallos 1997).

Cuadro 1. Producción y área sembrada de papa en América Latina, 1997-99

\begin{tabular}{|c|c|c|c|c|c|c|}
\hline \multirow{2}{*}{ Subregión país } & \multicolumn{3}{|c|}{ 1997-99 } & \multicolumn{3}{|c|}{ Tasa de crecimiento* } \\
\hline & $\begin{array}{l}\text { Prod. } \\
\text { (000t) }\end{array}$ & $\begin{array}{l}\text { Área } \\
(000 t)\end{array}$ & $\begin{array}{l}\text { Rendi- } \\
\text { miento } \\
\text { (t/ha) }\end{array}$ & $\begin{array}{l}\text { Prod. } \\
(\%)\end{array}$ & $\begin{array}{c}\text { Área } \\
(\%)\end{array}$ & $\begin{array}{c}\text { Rendi- } \\
\text { miento } \\
(\%)\end{array}$ \\
\hline Cono Sur & 7,190 & 365 & 19.7 & 1.9 & -0.8 & 2.7 \\
\hline Brasil & 2,760 & 177 & 15.6 & 2.5 & -0.3 & 2.8 \\
\hline Argentina & 3,314 & 115 & 28.8 & 2.1 & -1.1 & 3.2 \\
\hline Chile & 967 & 62 & 15.7 & 0.5 & -1.1 & 1.6 \\
\hline Uruguay & 147 & 11 & 13.4 & 0.9 & -1.7 & 2.7 \\
\hline Paraguay & 2 & 0 & 6.2 & -2.5 & -4.0 & 1.5 \\
\hline Zona Andina & 6,921 & 641 & 10.8 & 2.5 & 1.0 & 1.5 \\
\hline Colombia & 2,657 & 167 & 16.0 & 3.9 & 2.7 & 1.2 \\
\hline Perú & 2,679 & 263 & 10.2 & 2.2 & 0.3 & 1.8 \\
\hline Bolivia & 704 & 131 & 5.4 & 0.8 & 0.5 & 0.3 \\
\hline Ecuador & 566 & 62 & 9.2 & 1.9 & 1.8 & 0.1 \\
\hline Venezuela & 315 & 18 & 17.3 & 3.2 & 0.9 & 2.3 \\
\hline México & 1,367 & 64 & 21.3 & 3.7 & 0.8 & 2.9 \\
\hline $\begin{array}{l}\text { Centroamérica y } \\
\text { Caribe }\end{array}$ & 529 & 34 & 15.8 & 3.9 & 2.2 & 1.6 \\
\hline Cuba & 330 & 17 & 19.3 & 3.5 & 2.0 & 1.5 \\
\hline Costa Rica & 90 & 4 & 22.0 & 4.8 & 2.5 & 2.2 \\
\hline Guatemala & 58 & 8 & 7.2 & 3.8 & 2.2 & 1.6 \\
\hline Nicaragua & 28 & 2 & 13.6 & 8.6 & 4.6 & 3.8 \\
\hline Rep. Dominicana & 23 & 2 & 10.1 & 3.3 & 2.4 & 0.9 \\
\hline Otros & 65 & 5 & 13.3 & 2.7 & 1.1 & 1.5 \\
\hline $\begin{array}{l}\text { Total América } \\
\text { Latina }\end{array}$ & 16,072 & 1,108 & 14.5 & 2.4 & 0.3 & 2.1 \\
\hline
\end{tabular}

Fuente: FAOSTAT, 5 de abril del 2000.

'Promedio anual 1961 -63 a 1997-99.

Otra tendencia sobresaliente de la oferta de papa se relaciona con los cambios en el sistema de comercialización interna. Las mejoras en la infraestructura de éste -como la construcción de mercados mayoristas modernos, mejores carreteras y más completos sistemas de información agrícola- han sido claves para el desarrollo de un sector papero cada vez más comercial. Ejemplos de esto son la evolución del sistema de 
transporte de papa en Perú y la construcción de mercados mayoristas que facilitan el ingreso del producto al mercado en el caso de Colombia (Rodríguez 1996), Costa Rica (Scott 1996), México (Biarnes et al. 1995) y Argentina (Maggi 1990). También se nota el establecimiento de mejores sistemas de información agrícola en general, y de papa en particular, en países como Colombia, Costa Rica (Scott 1996) y Argentina (Inchausti 1987; Maggi 1990).

Cuadro 2. Producción de papa de los países en desarrollo por regiones, 1997-99

\begin{tabular}{|c|c|c|c|c|c|c|}
\hline \multirow[b]{2}{*}{ Región } & & 1997-99 & & \multicolumn{3}{|c|}{$\begin{array}{c}\text { Tasa de crecimiento } \\
(\%)\end{array}$} \\
\hline & $\begin{array}{l}\text { Prod. } \\
\text { (000 1) }\end{array}$ & $\begin{array}{c}\text { Área } \\
\text { (000 ha) }\end{array}$ & $\begin{array}{c}\text { Rendi- } \\
\text { miento } \\
\text { (t/ha) }\end{array}$ & $\begin{array}{c}\text { Prod. } \\
1\end{array}$ & $\begin{array}{c}\text { Área } \\
2\end{array}$ & $\begin{array}{c}\text { Rendi- } \\
\text { miento } \\
3\end{array}$ \\
\hline África $^{\mathrm{D}}$ & 7,284 & 724 & 10.1 & 2.9 & 2.1 & 0.8 \\
\hline$(\text { Sub Sahara })^{c}$ & 2,727 & 458 & 5.9 & 1.7 & 2.4 & -0.7 \\
\hline Asiad $^{d}$ & 96,956 & 5,773 & 16.8 & 4.2 & 2.3 & 1.9 \\
\hline (China) & 57,804 & 3,430 & 16.9 & 4.1 & 2.2 & 1.9 \\
\hline América Latina ${ }^{\mathrm{e}}$ & 16,073 & 1,108 & 14.5 & 2.1 & 0.0 & 2.2 \\
\hline Total & 120,314 & 7,605 & 15.8 & 3.8 & 1.9 & 1.9 \\
\hline
\end{tabular}

Fuente: FAOSTAT, 5 de abril del 2000.

a Promedio anual (1978-80 vs. 1997-99).

${ }^{\mathrm{b}}$ No incluye Sudáfrica.

${ }^{0}$ África - (Marruecos, Algeria, Tunisia, Egipto, Libia) - Sudáfrica.

d Asia - (Japón, Kazajstán, Uzbekistán, Kyrgyzstán, Armenia, Israel, Georgia, Azerbaiyán, Tayikistán, Turkmenistán) + Oceanía - (Australia, Nueva Zelandia).

${ }^{\text {e }}$ América del Norte y Central + Sudamérica - (Canadá, Estados Unidos).

\section{Cambios globales y regionales en la demanda de la papa}

El proceso de globalización, en diferentes formas y por diferentes razones, también ha contribuido a cambios importantes en la demanda de papa a nivel mundial, incluyendo lo siguiente:

a. La caída en la demanda de papa fresca en Europa, como en el área ocupada por el ex Unión Soviética, acompañada por una fuerte expansión en la demanda de dicho producto en Asia, África y, en menor grado, en América Latina;

b. La reducción en el uso de la papa para la alimentación animal en Europa;

c. La retracción en la producción de almidón de papa en Europa 
d. El fuerte crecimiento en la demanda para productos procesados de papa (hojuelas, papas fritas) en América del Norte, en ciertos países de Europa y también en ciertas partes de los países en desarrollo.

Según la FAO (1995), el consumo per cápita promedio de papa en Europa Occidental cayó de $102.3 \mathrm{~kg} / \mathrm{año}$ en 1961-63 hasta $67.4 \mathrm{~kg} / \mathrm{año}$ en 1991-92; y en la ex URSS cayó de $131.8 \mathrm{~kg} / \mathrm{año}$ a $78 \mathrm{~kg} / \mathrm{año}$ por los mismos años. Durante el mismo tiempo, el consumo per cápita de papa en los países en desarrollo subió de 8.6 a $12.3 \mathrm{~kg} / \mathrm{año}$-a pesar del fuerte crecimiento en la población. Más aún, en Asia el consumo de papa per cápita aumentó de 12 $\mathrm{kg}$ en 1991-92 a $14 \mathrm{~kg}$ en 1994-96; un aumento del 16\% en términos per cápita durante los últimos tres años (Scott y Maldonado 1998). En África, el consumo promedio anual permaneció alrededor de $8 \mathrm{~kg} / \mathrm{año}$ per cápita durante el mismo período porque el aumento constante en la producción agregada ha sido acompañado por un rápido y continuo crecimiento de la población (ibid.). Para América Latina, el consumo per cápita aumentó casi $15 \%$ en los últimos años (de $21 \mathrm{~kg} / \mathrm{año}$ a $24 \mathrm{~kg} / \mathrm{año}$ ). Los razones para estas tendencias opuestas son múltiples, pero los principales son: i) el aumento de ingreso y ii) el deseo de los consumidores de diversificar sus dietas -para los de Europa del Oeste, de papa a otros alimentos, p.ej. a granos más finos; y para los de Asia, de puros cereales a una alimentación que incluye más productos hortícolas, de los cuales la papa tiene un status muy elevado (véase Scott et al. 2000; Woolfe 1987).

La reducción en el uso de papa en la alimentación animal en Europa refleja cambios estructurales en la producción animal. Desde luego, el proceso está mucho más avanzado en Europa Occidental que del Este, pero se trata básicamente del cambio en la producción de puercos en pequeñas fincas familiares a grandes agroempresas especializadas, las cuales utilizan raciones concentradas de cereales en lugar de papa como la base de la dieta animal, para ser más eficientes y satisfacer la demanda de carne (véase Horton y Anderson 1992; FAO 1995).

En América Latina, los cambios en la demanda de papa se manifiestan por una serie de razones y factores. Por un lado, la estructura de la demanda de alimentos en la región ha variado, al crecer la de productos procesados. Entre los fenómenos socioeconómicos más significativos detrás de este proceso están los cambios en los patrones de consumo y en el ritmo de vida, por el acelerado crecimiento de la población urbana en la mayoría de los países latinoamericanos, la creciente incorporación de la mujer al mercado laboral formal, el incremento de los ingresos reales en algunos países, el aumento del turismo en la región, el auge en las comunicaciones (masivas) y la creciente influencia de la cultura occidental en el estilo de vida y los patrones de consumo de los habitantes de América Latina (Scott 1994). Esos fenómenos no han tenido mayor impacto sobre la demanda de papa para alimentación anima! o para almidón: salvo en algunos casos excepcionales, no han 
resultado de importancia, pero sí han influido mucho en la demanda de papa procesada.

Dichos cambios en la demanda han representando un fuerte estímulo para el desarrollo de la agroindustria de papa en muchos países de la región. En la actualidad, la industria de procesamiento en Colombia absorbe aproximadamente 250 mil toneladas de papa de una cosecha total de 2.7 millones (Augusto de Valle, comunicación personal). En México se estima que entre el 16 y el $19 \%$ de la producción se destina al mercado interno urbano en forma de productos procesados por la industria alimentaria (Biarnes et al 1995).

Ante la demanda de los nuevos productos, el interés del sector privado no se ha hecho esperar. Argentina, por ejemplo, se está convirtiendo en receptor de significativas inversiones extranjeras para dinamizar la demanda de'papa procesada, además de alentar una mayor participación del sector privado nacional. En este país se instaló una planta transnacional procesadora de papa con un costo de US\$25 millones y, según observadores nacionales, también Chile, Colombia, Ecuador y Perú estarían recibiendo inversiones extranjeras y nacionales para dicha actividad (FAO 1995; Maldonado y Scott 1997). Pero aquí también hay una notable diferencia. Argentina y Colombia son los únicos países en toda la región donde había construcción de fabricas para procesar papas fritas congeladas en los últimos años. En los otros países mencionados, las inversiones han sido para producir hojuelas de papa. Los especialistas indican que esta dicotomía refleja la importancia primordial de los costos de materia prima en el caso de papas congeladas versus el caso de hojuelas, donde los costos de transporte de producto final tienen mayor peso.

El impresionante crecimiento de la industria de comida rápida (fast-food) es parte de esta tendencia. Un indicador de ello es el significativo aumento del número de restaurantes de la cadena transnacional McDonald's en los países latinoamericanos, donde en menos de un decenio aumentaron 1,700\%, al pasar de 99 a 1789 (Cuadro 3) Tendencias similares se observan con cadenas de restaurantes nacionales, como el caso de una guatemalteca, que pasó de 27 restaurantes en 1992 a 48 en 1996 (Koop 1992; Scott 1996).

Todos estos cambios en la oferta y demanda de papa en la región han modificado los patrones de importación y exportación al incorporar nuevos productos y diversificar el intercambio comercial, tanto intrarregional como con los países en desarrollo. 
Cuadro 3. Restaurantes McDonald's por país y región, 1987 vs. 1999

País/región
\begin{tabular}{|lcc|}
\hline Total Asia / Pacífico & 1987 & 1999 \\
\hline Total Europa / África & 951 & 5,655 \\
Total América Latina & 755 & 5,392 \\
Argentina & 99 & 1,789 \\
Brasil & 3 & 205 \\
Colombia & 37 & 921 \\
Costa Rica & 0 & 21 \\
Chile & 4 & 22 \\
Guatemala & 0 & 61 \\
México & 3 & 27 \\
Panamá & 5 & 170 \\
Puerto Rico & 8 & 23 \\
Uruguay & 22 & 121 \\
Venezuela & 0 & 32 \\
Otros & 3 & 83 \\
Estados Unidos & 14 & 103 \\
Canadá & 7,567 & 12,629 \\
Total número de restaurantes & 539 & 1,125 \\
\hline
\end{tabular}

Fuente: McDonald's Annual Report (1992, 1999) (Las cifras para 1999 y fueron tomadas de la web de McDonald's ).

\section{El comercio exterior}

América Latina es la única región de países en desarrollo con un déficit comercial en papa. Las importaciones de papa consumo y semilla excedieron las exportaciones por casi 200,000 toneladas durante 1996-98 (FAOSTAT 2000), con un total de importaciones que alcanzó 307,000 toneladas, alrededor de $2 \%$ de la producción regional (Cuadro 4). Aunque las estadísticas son aproximaciones y las cifras no siempre están disponibles para los mismos períodos de tiempo, la reciente información sobre importaciones de papas fritas congeladas (Cuadro 5), sumada a la información inicial sobre papa consumo y semilla, implica que el porcentaje total es mayor y su tasa de crecimiento sigue a un ritmo mayor. La masa -que no significa la totalidad- de esas importaciones proviene de países industrializados como Canadá, Holanda y los Estados Unidos. La mayor diferenciación de los mercados regionales de importación y exportación implica que dichas tendencias requieren una mayor revisión a nivel subregional y nacional. 
Cuadro 4. América Latina y el Caribe: comercio exterior de papa, 1961-63 y 1996-98? (miles de toneladas)

\begin{tabular}{|c|c|c|c|c|}
\hline \multirow{2}{*}{ Subregión / país } & \multicolumn{2}{|c|}{$1961-63$} & \multicolumn{2}{|c|}{$1996-98$} \\
\hline & $\begin{array}{c}\text { Exporta- } \\
\text { ciones } \\
(000 \mathrm{t})\end{array}$ & $\begin{array}{l}\text { Importa- } \\
\text { ciones } \\
(000 \mathrm{t})\end{array}$ & $\begin{array}{l}\text { Exporta- } \\
\text { ciones } \\
(000 \mathrm{t})\end{array}$ & $\begin{array}{c}\text { Importa- } \\
\text { ciones } \\
(000 \mathrm{t})\end{array}$ \\
\hline Cono Sur & 20 & 100 & 59 & 78 \\
\hline Argentina & 13 & 49 & 55 & 2 \\
\hline Brasil & 0 & 6 & 0 & 54 \\
\hline Uruguay & 0 & 41 & 1 & 17 \\
\hline Otros & 7 & 5 & 2 & 5 \\
\hline Zona Andina & 2 & 14 & 17 & 67 \\
\hline Colombia & 2 & 0 & 13 & 9 \\
\hline Venezuela & 0 & 14 & 0 & 58 \\
\hline Otros & 0 & 0 & 5 & 1 \\
\hline México & & 2 & 2 & 42 \\
\hline Centroamérica y & 6 & 84 & 37 & 120 \\
\hline $\begin{array}{l}\text { Caribe } \\
\text { Cuba }\end{array}$ & & 33 & 1 & 33 \\
\hline Guatemala & 4 & 0 & 30 & 0 \\
\hline Nicaragua & 0 & 0 & 0 & 14 \\
\hline Otros & 2 & 50 & 5 & 72 \\
\hline Total & 28 & 200 & 114 & 307 \\
\hline
\end{tabular}

Fuente: FAOSTAT, 11 de noviembre de 1999.

${ }^{a}$ Referido sólo al comercio de papa fresca y papa semilla.

Son muchos los factores que contribuyen al aumento de las importaciones de papa y sus productos derivados. Por el lado de la demanda de productos procesados, una mayor población urbana y un incremento de los ingresos per cepita han generado cambios en las dietas alimenticias -alrededor de $70 \%$ de todos los consumidores de América Latina residen, actualmente, en áreas urbanas y muchas amas de casa tienen la capacidad de adquirir más productos procesados. El crecimiento de la participación femenina en la actividad laboral y la disminución del tiempo para almorzar tienen simultáneamente un efecto positivo sobre la demanda de alimentos de fácil preparación. La explosión del turismo ha traído nuevas influencias sobre la demanda local de alimentos, de forma directa e indirecta por los extranjeros y sus hábitos de consumo sobre los consumidores locales. La veloz expansión de la industria de la comida rápida o fast-food, tanto de las cadenas locales como las extranjeras, con sus respectivas agresivas campañas publicitarias (Cuadro 3), también es un factor que influye en la demanda de productos procesados de papa. 
Cuadro 5. América Latina y el Caribe: importaciones de papas fritas congeladas ${ }^{3}$ (toneladas)

\begin{tabular}{|ccc|ccccccc|}
\hline \multicolumn{9}{c}{$1991-92$} & \multicolumn{3}{c|}{$1994-95$} \\
& $\begin{array}{c}\text { Estados } \\
\text { Unidos }\end{array}$ & $\begin{array}{c}\text { Países } \\
\text { Bajos }\end{array}$ & Canadá & Total & $\begin{array}{c}\text { Estados } \\
\text { Unidos }\end{array}$ & $\begin{array}{c}\text { Países } \\
\text { Bajos }\end{array}$ & Canadá & Total \\
\hline Cono Sur & 503 & 997 & 1,333 & 2,833 & 18,722 & 10,651 & 21,799 & 51,173 \\
Brasil & 218 & 987 & 575 & 1,780 & 12,159 & 5,986 & 13,874 & 32,019 \\
Chile & 134 & 10 & 108 & 252 & 3,726 & 612 & 2,192 & 6,529 \\
Uruguay & - & 10 & 149 & 159 & 930 & 3,483 & 1,016 & 5,429 \\
Argentina & 150 & - & 502 & 653 & 1,908 & 572 & 4,717 & 7,196 \\
Zona Andina & 1,543 & - & 1,320 & 2,863 & 3,587 & 42 & 8,898 & 12,527 \\
Ecuador & 20 & - & - & 20 & 947 & - & 16 & 963 \\
Colombia & 7 & - & 16 & 24 & 191 & 42 & 495 & 729 \\
Perú & - & - & 83 & 83 & 220 & - & 1,608 & 1,828 \\
Venezuela & 1,516 & - & 1,221 & 2,737 & 2,229 & - & 6,778 & 9,007 \\
Centro América & 6,109 & 1,493 & 4,910 & 12,512 & 14,599 & 1,842 & 15,518 & 31,959 \\
y el Caribe & & & & & & & & \\
Guatemala & 428 & - & 19 & 447 & 3,942 & - & 3,140 & 7,082 \\
Antillas & 359 & - & 1,317 & 1,676 & 1,543 & - & 2,715 & 4,258 \\
Holandesas & & & & & & & & \\
El Salvador & 227 & - & - & 227 & 1,492 & - & - & 1,492 \\
Jamaica & 480 & - & - & 480 & 1,399 & - & 1,715 & 3,114 \\
Honduras & 316 & - & - & 316 & 1,210 & - & 349 & 1,559 \\
Islas & 36 & - & - & 36 & 302 & - & - & 302 \\
Vírgenes & & & & & & & & \\
Británicas & & & & & & & & \\
Bahamas & 2,317 & - & 435 & 2,752 & 801 & - & 577 & 1,378 \\
Rep & 73 & - & 116 & 189 & 794 & 55 & - & 849 \\
Dominicana & & & & & & & & \\
Costa Rica & 314 & - & - & 314 & 609 & - & - & 609 \\
Otros b & 1,560 & 1,493 & 3,139 & 6,192 & 2,506 & 1,787 & 7,022 & 11,315 \\
México & 14,618 & - & 540 & 15,158 & 33,316 & - & 1,155 & 34,470 \\
Total & 22,773 & 2,490 & 8,103 & 33,366 & 70,224 & 12,535 & 47,370 & 130,129 \\
\hline & & & & & & & &
\end{tabular}

Fuente: U.S. National Potato Board, Informe preparado por Trade Stats Northwest/Pacific Vision, 1996.

${ }^{a}$ Con base en el peso fresco utilizando una libra de papa congelada como equivalente a dos libras de papa fresca y convertido a toneladas métricas.

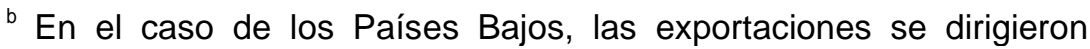
principalmente a Curazao, Aruba, Martinica, Guadalupe, Haití, Anguilla y Bahamas; en el de Canadá, a Trinidad y Tobago, Jamaica, Bermuda, Barbados y Cuba.

Por el lado de la oferta, una combinación de factores ha hecho a los productos importados de papa procesada más competitivos. Las importaciones han sido facilitadas por las siguientes razones:

a. Los precios disminuyen a la par de la reducción de los aranceles.

b. Las economías de escala en las grandes plantas de procesamiento para papas fritas y almidón en los países exportadores e industrializados influyen en el costo de producción. 
c. Existe abundancia, si no es una sobreoferta, de materia prima en los países industrializados (New York Times 1997) y un plan de promoción de las exportaciones.

d. Los grandes embarques disminuyen los costos de transporte de larga distancia (The Economist 1997). Al mismo tiempo, los productos procesados producidos localmente han perdido participación de mercado por los altos costos unitarios que presentan los productores y la mínima articulación 0 interacción entre productores, procesadores y consumidores. A la par de estas tendencias, algunos países de América Latina también han ingresado al comercio de papa como exportadores por muchas de las mismas razones.

Con el crecimiento de la población, las áreas urbanas y el turismo, y un esperado incremento de los ingresos per cápita en las décadas venideras, las preguntas que surgen son: ¿cuál es el mejor escenario para la futura evolución del comercio de papa en América Latina? y, quizá la más importante, ¿qué pueden hacer los países con limitados recursos para la investigación y el desarrollo del sector papero para mejorar esta situación?

Dado el amplio rango de participantes, una tipología de los países podría ayudar a esclarecer las opciones relevantes al alcance para cada tipo de país.

\section{Tipología agroindustrial de los países}

Para el propósito de este análisis, los países que participan en la agroindustria y el comercio exterior de papa podrían ser agrupados en varias categorías: importadores (grandes y pequeños productores), exportadores y comercializadores menores.

\section{Grandes productores importadores}

Los primeros ejemplos de esta categoría son México y Brasil. Cada uno cuenta con un inmenso sector papero. Sin embargo, este producto no es el principal cultivo. Ambos presentan este sector dividido, en una menor parte, por producción a gran escala con tecnología avanzada, y una mayor conformada por pequeños agricultores (campesinos). Ambos países presentan una gran población, un mayor ingreso per cápita en relación a los demás países de la región y han presenciado una veloz expansión en el comercio de la comida rápida en los recientes años (Cuadro 3). Ninguno ha visto una expansión en su capacidad de producir papa congelada a nivel industrial. Cada uno de ellos cuenta con un gran productor de papa como vecino, el cual es proveedor de sus importaciones. Asimismo, cada país pertenece'a un bloque comercial regional (NAFTA y MERCOSUR, respectivamente) y ambos han visto crecer sus importaciones de papa fresca y procesada por la disminución de los aranceles debido a su participación en el bloque comercial. 
El caso mexicano es particularmente notable porque los actuales aranceles para papas frescas son de $200 \%$. Sin embargo se ha programado que para el 2004 estos aranceles bajen a cero. A pesar de que los aranceles para las papas procesadas son sólo una fracción del que afecta a la papa fresca, las cuotas no permiten importaciones ilimitadas. Las importaciones en general -en México y más recientemente en Brasil- se han estancado temporalmente por razones fitosanitarias y de devaluaciones. No obstante, las importaciones de papa han continuado creciendo durante el mismo período (Cuadro 6). Estudios recientes sugieren que, dadas las diferencias en el costo de producción y el crecimiento en la demanda por papas, las importaciones de este producto podrían crecer considerablemente en los próximos años. Al mismo tiempo, los significativos mejoramientos en la productividad podrían hacer crecer la competitividad en el mercado fresco, tomando ventaja de las preferencias locales por variedades no desarrolladas al norte de la frontera, y explotar la posibilidad de cosechar todo el año. Además, estas iniciativas podrían estar relacionadas con los esfuerzos por fortalecer algunos componentes de la industria del procesamiento de papa (por ejemplo, las plantas productoras de hojuelas de mediana escala) y así explotar los segmentos emergentes en el mercado regional local para papas procesadas, de esta manera se satisface la creciente demanda con importaciones y productos producidos localmente.

Cuadro 6. México: importaciones de papa provenientes de Estados Unidos de América por tipo de producto, en miles de tm, y porcentaje de la distribución del producto

\begin{tabular}{|ccccc|}
\hline & $1990-92$ & $\%$ & $1994-96$ & $\%$ \\
\hline Fresca & $\mathbf{1 5}$ & 36 & $\mathbf{2 2}$ & $\mathbf{2 5}$ \\
Congelada & $\mathbf{1 1}$ & 29 & 34 & 39 \\
Hojuelas & 9 & 23 & 16 & 18 \\
Otros & 5 & 12 & 15 & 18 \\
Total & 40 & 100 & 87 & 100 \\
\hline
\end{tabular}

Fuente: USDA (1991-92).

\section{Pequeños productores importadores}

Estos países se encuentran en el Caribe, las Guyanas y América Central, a excepción de Guatemala y Venezuela. Las papas no son, generalmente, gran parte de la dieta alimenticia y, con excepción de Cuba y Venezuela, son producidas por un pequeño número de agricultores para ser vendidas en el mercado fresco como un vegetal caro y de lujo. Las importaciones de los productos procesados de papa están creciendo en muchas instancias, simplemente porque el sector papero local es muy pequeño y los precios al productor de las papas frescas son demasiado altos para justificar económicamente el 
procesamiento, ni siquiera por una empresa doméstica. La demanda se ha desarrollado rápidamente por el incremento en los ingresos, un mayor turismo y la aparición de los restaurantes de comida rápida que atienden a los consumidores locales y a los extranjeros. Las menores tasas arancelarias y fletes han permitido que las importaciones sean baratas.

Algunos países -particularmente Costa Rica, Panamá y Venezuela- han visto incrementar sus importaciones de papa consumo en períodos particulares, cuando la escasez de los productos locales generan precios muy altos (López 1993; Scott 1996). Frente a esta situación, la respuesta ha sido reinstaurar temporalmente aranceles más altos para desalentar la inundación del mercado local con importaciones, pero estas medidas ad hoc han generado controversias porque provocan pagos convenidos por los que participan en las transacciones.

En muy pocos casos la semilla representa la mayor participación en las importaciones de papa. Esto sucede en Cuba, Nicaragua y Venezuela. Generalmente, los programas de papa en esos países se han pronunciado frente al incremento de las importaciones de papa con un llamado a la expansión de la industria de procesamiento de papas fritas, hojuelas, almidón y hasta papas al hilo. En caso contrario tienen que apelar a las autoridades gubernamentales para reinstaurar barreras arancelarias. Una alternativa próxima podría ser la canalización de los limitados recursos locales para mejorar el desempeño de los agricultores que se encuentran dentro del sistema de producción de papa consumo. Las ventajas comparativas en relación a las importaciones consisten en que algunos consumidores siempre preferirán mayor calidad en tubérculos frescos producidos localmente, y que muchas localidades, por sus condiciones climáticas, cuentan con una producción continua durante todo el año. Esta tarea puede ser complementada con esfuerzos focalizados en un único segmento de la industria de procesamiento con mayor potencial, así como las hojuelas de papa con una sazón local, afiliada a una marca, con técnicas de producción a escala. Con ello se podría capturar un significativo, aunque no predominante, segmento del mercado local.

\section{Exportadores}

Este grupo de países está conformado por Argentina, Colombia y Guatemala. El primero exporta a Brasil, Venezuela y Ecuador, mientras que Colombia exporta a El Salvador y Guatemala a Nicaragua.

Las exportaciones de papa consumo de Argentina a Brasil llegaron a 160,000 toneladas en 1994 con la apertura del MERCOSUR y la reducción de los aranceles. Muchas de estas papas son distribuidas desde el norte de Argentina al sur de Brasil cuando la cosecha temprana de papa a un lado de la frontera coincide con precios estacionales altos y escasez en los mercados mayores, como el de Sao Paulo. Con la apertura de una gran planta multinacional de procesamiento de papas 
fritas en Balcarce, a inicios de 1995, y el incremento de su línea de producción, recientemente las exportaciones de Argentina han incluido también papas fritas congeladas. Los grandes productores en Argentina, con alta tecnología y amplio financiamiento, continuarán presionando a los pequeños agricultores (campesinos) de los estados del sur de Brasil, como Paraná, que dependen de una agricultura de lluvias para su subsistencia. La reciente devaluación de $30 \%$ en la moneda brasileña dará a estos productores un periodo de calma, aunque quizá sólo sea temporalmente.

Las exportaciones colombianas de papa consumo y semilla a Ecuador y Venezuela están fundamentadas en lo siguiente: mayores rendimientos y menores costos unitarios de producción, aunque éstos son sensibles a la tasa de cambio; una buena organización de productores, comerciantes y distribuidores; y una buena red de infraestructura para el mercadeo: caminos, mercados mayoristas y telecomunicaciones (Scott, Basay y Maldonado 1997). En años recientes, dichas exportaciones han sido suspendidas por razones fitosanitarias, aunque lo más probable es que sea una suspensión temporal.

Argentina y Colombia, en particular, han iniciado una agresiva campaña para lograr una creciente participación en el mercado de exportación subregional. Estos esfuerzos han incluido:

a. Estrecha colaboración en investigación por parte del sector público y privado (Rodríguez y Rodríguez 1992).

b. Políticas que impulsen la expansión de la infraestructura de los procesadores; por ejemplo, incentivos para invertir y reducción tributaria.

c. Buscar desarrollar o lograr variedades de papa mejorada para procesamiento como parte de un plan integrado que fortalezca la competitividad en todos los aspectos del sistema alimenticio de papa: variedades, semillas, producción de materia prima, equipamiento y facilidades para planta, infraestructura de mercado (por ejemplo, puertos, telecomunicaciones) y políticas de comercio e inversión.

\section{Comercializadores menores}

Esta categoría incluye a Solivia, Chile, Perú y Paraguay. Estos países, tradicionalmente, no han importado (porque son autosuficientes) ni exportado papas en cantidades significativas (porque producen muy poco y lo que envían al exterior es simplemente embarques que transitan desde otros países). Sin embargo, han experimentado algunas posibilidades de exportación (Fano et al. 1998; Muchnik and Tejo 1997).

Aunque en años recientes estos países han visto un incremento de sus importaciones de papa, tanto frescas como procesadas, dichos volúmenes se han mantenido pequeños. Ellos han atraído la atención en la prensa dada su estratégica presencia en un mercado papero de rápido 
crecimiento que se explica por su reciente inclusión como miembros partícipes del MERCOSUR. Sin embargo, por ambos tipos de productos, dados los altos niveles de consumo per cápita y el gran número de consumidores urbanos de bajos ingresos, la amenaza de los grandes importadores de papas frescas y procesadas que son más baratas que las producidas localmente tendrá que ser considerada seriamente en el mediano plazo. En ese sentido existen varias medidas que merecen ser evaluadas.

En el ciclo de la producción, estos países pueden mejorar sus rendimientos de las variedades que son preferidas localmente y lograr explotar la posibilidad de cosechar papa todo el año. En relación a la poscosecha, ambos países pueden tomar ventaja de las innovaciones recientes en el procesamiento, como es el caso de los productos de papa en frío, en lugar de congelados (Scott 1998). Como política inicial se puede promover la actualización y modernización de la infraestructura para el procesamiento de papa, dentro de la industria local y extranjera, mediante incentivos tributarios y de inversión. Todas estas medidas podrían proporcionar complementos estratégicos para trabajar a largo plazo el desarrollo de variedades mejoradas, así como semillas elaboradas más eficientes y resistentes.

\section{Conclusiones}

Varios indicadores muestran que la agroindustria y el comercio de la papa en América Latina se expandirán rápidamente en las siguientes décadas. Algunos países latinoamericanos han sido testigos de una mayor expansión de sus importaciones y sus exportaciones que muchos otros. De esta experiencia colectiva parten las siguientes recomendaciones:

a. Tener como objetivo la investigación y el desarrollo de esfuerzos para captar un segmento particular del mercado local (sustitución de importaciones) 0 de exportación para papa procesada antes que propuestas que involucren diversos segmentos simultáneamente. El segmento más apropiado para los países será determinado en base de la situación y trayectoria del sector nacional con relación a una tipología regional.

b. Contar con mayor información referente al modo en el que definen los destinos del flujo comercial los países vecinos o los demás países latinoamericanos -incluyendo los desarrollos en los países industrializados en relación a la tendencia por papas en frío, así como los casos de éxito y fracaso de dicha actividad. A la vez, mantenerse más informados sobre las últimas tendencias y convenios comerciales en términos de reducciones arancelarias relativas a los diferentes productos de la papa para mejorar la base de la estrategia local. 
c. Considerar el comercio de algunas líneas de producción desde la perspectiva de todo el sistema. Esto incluye no sólo el esfuerzo relacionado al incremento de la productividad, sino también aminorar los procesos y los costos de producción y mejorar la calidad. Inevitablemente esto está ligado a la búsqueda de mejores variedades, lo cual involucra la participación de todos aquellos que tienen que ver con el mejor desempeño del sistema de producción, incluyendo la empresa privada (por ejemplo, los proveedores de insumos, los mayoristas y los procesadores de papa), la asociación de productores y los funcionarios públicos no sólo del sector agrícola, sino también los ministerios de comercio e industria.

d. Desarrollar aspectos técnicos y físicos de la producción (por ejemplo, nuevas variedades), comercialización (carreteras) y procesamiento (plantas), pero también y simultáneamente aspectos legales (contratos y leyes sobre el uso de patentes).

\section{Bibliografía}

Biarnes, A.; J.P. Colin; García Mata, R. y De Jesús Santiago Cruz, M. 1995. Agroeconomía de la papa en México. ORSTOM, México.

Fano, H.; Carmena, G; Ordinola, M.; y Scott, G. 1998. Experiencias de exportación de la papa amarilla peruana. Departamento de Ciencias Sociales. Documento de Trabajo No. 1998-3. International Pótalo Center (CIP), Lima.

FAO (Food and Agriculture Organization of the United Nations). 1995. La papa en la década de 1990. Situación y perspectivas de la economía de la papa a nivel mundial. CIP-FAO, Roma. 39 págs.

2000. FAOSTAT Statistics Datábase (Online). Various months. Available HTTP: HYPERLINK http://apps.fao.org http://apps.fao.org

Horton, D. y Anderson, J. 1992. "Potato production in the context of the world and farm economy". In The potato crop. The scientific basis for improvement, de. P. Harris. Chapman y Hall, London.

Inchausti, M. 1987. Funcionamiento del mercado central de Buenos Aires: su incidencia en la eficiencia del proceso de comercialización de papa. Tesis para optar el título de Ingeniero Agrónomo en la Facultad de Ciencias Agrarias de la Universidad de Mar del Plata, Balcarce, Argentina.

Koop, M.A. y Burgos, S. 1992. "Utilización, procesamiento y co mercialización de la papa en Pollo Campero S.A" en: Desarrollo de productos de raíces y tubérculos. Volumen II-América Latina, op.cit., pp.351-353.

López, E. 1993. "Papa: a la conquista del mercado venezolano" en Revista Nacional de Agricultura, núm.902, pp. 166-169. 
Maldonado, L. y Scott, G. 1997. "El comercio exterior de papa y América Latina" en Agro Enfoque, Edic. 91, diciembre 1997, Lima.

Maggi, C. 1990. La comercialización de batata en la Argentina: un estudio basado en información del Mercado Central de Buenos Aires, Instituto Nacional de Tecnología Agropecuaria (INTA) e Instituto de Economía y Sociología Rural (IESTR). Argentina.

Mayer, E. (compilador), S.B. Brush, M. Glave, E. Mayer y J.E. Taylor. 1992. La chacra de papa: economía y ecología. Centro Peruano de Estudios Sociales (CEPES), Lima.

McDonalds' Corporation. 1992 and 1999. Annual report to shareholders Oakbrook. IL, USA.

Muchnik, E. y Tejo, P.1997. La papa en el comercio regional y en los acuerdos regionales. Documento preparado para la Comisión Económica para América Latina y el Caribe(CEPAL). CEPAL, Santiago de Chile.

New York Times. 1997. Anxious days in Potatoland: Competitive forces threaten to knock Idaho from top. 12 March 1997.

Pacific Vision. 1996. Report prepared for the U.S. National Pótalo Board. Trade Stats Northwest / Pacific Vision, Portland, OR, USA.

Rodríguez, P. 1996. La papa y el desarrollo económico en Colombia. CIPCORPOICA, Lima.

Rodríguez, P. y Rodríguez, A. 1992. "Algunos aspectos de la industrialización de papa en Colombia" en Papa, núm.5, pp.4-7.

Scott, G.J. 1994. "The emerging world market for polatoes and potato producís with particular reference lo developing countries" en Economie et Gestión Agro-Alimentaire, núm. 30, enero, pp.19-27.

1996. Informe sobre la industrialización de la papa del Programa Regional Cooperalivo de Papa (PRECODEPA), CIP, Lima, abril, (mimeo).

_. 1998. "Los fasl foods aumenlan demanda de la papa procesada". Síntesis, 24.2.98. Lima.

Scott, G.J.; R. Basay y L. Maldonado. 1997. "El comercio exterior de papa en América Lalina". Comercio Exterior. Vol. 47(12) pp. 984-996.

Scott, G.J. y L. Maldonado. 1998. La papa en cifras. Un compendio de información clave y análisis para 32 importantes países productores de papa. Centro Internacional de la Papa (CIP), Lima.

Scott, G.J.; Rosegranl, M. y Ringler, C. 2000. Raíces y tubérculos para el siglo XXI: tendencias, proyecciones y alternativas para la política. Documento de Discusión 2020. International Food Policy Research 
Institute (IFPRI) y Centro Internacional de la Papa (CIP), Washington DC.

The Economist. 1997. "Delivering the goods". 15 November 1997, pp. 85-86.

Thiele, G.; Bustamente, J.; Mansilla, J. y Scott, G. 1998. Los precios de papa, arroz y trigo en Bolivia: un análisis del período 1980-96. Centro Internacional de la Papa (CIP), Departamento de Ciencias Sociales. Documento de Trabajo No. 1998-6. CIP, Lima.

USDA (U.S.Dept. of Agriculture). 1991-97. Pótalo facts. Economic Research Service, USDA, Washington, D.C.

Woolfe, J. 1987. The potato in the Human Diet. Co-published by the International Potato Center. (CIP) Lima, Perú, and Cambridge University Press, Cambridge, U.K.

Zevallos, H. 1997. Aspectos económicos de la producción de la papa en Bolivia. Co-published by the International Potato Center (CIP) and Agencia Suiza para el Desarrollo y la Cooperación (COSUDE). CIP, Lima. 